\title{
Los derechos humanos y el problema de la cárcel en Colombia: Una perspectiva de lectura genealógica*
}

\author{
Human rights and the problem of prison in Colombia:
}

A genealogical reading perspective

Alexánder Hincapié García ${ }^{\mathbf{}}$, Kelly Johana Henao Castrillón ${ }^{2 凶}$ Delio Antonio Cardona Montoya ${ }^{3 \mathbf{z}}$

Fecha correspondencia:

Recibido: 22 de octubre de 2019.

Revisión: 29 de julio de 2020.

Aceptado: 30 de julio de 2020.

Forma de citar:

Hincapié, Alexánder; Henao,

Kelly Johana; Cardona, Delio

Antonio. "Los derechos humanos

y el problema de la cárcel en

Colombia: Una perspectiva de

lectura genealógica." En: Revista

CES Derecho. Vol. 11, №. 2, junio a

diciembre de 2020, 70-87.

Open access

Términos de uso

Licencia creative commons

Etica de publicaciones

Revisión por pares

Gestión por Open Journal System

DOl: http://dx.doi.org/10.21615/

cesder.11.2.5

ISSN: 2145-7719

Sobre el artículo:

Artículo asociado a la investigación terminada Los cuerpos de

la excepción. Investigación

financiada por la Universidad de San Buenaventura Medellín y la Universidad Autónoma Latinoamericana. Código: FTINV-012. Actas de inicio firmadas

\section{Resumen}

Este artículo está asociado a la investigación finalizada Los cuerpos de la excepción. Su propósito consiste en enfrentar la perspectiva de lectura genealógica con la perspectiva de los Derechos Humanos, en torno al problema de la cárcel en Colombia. El argumento central sostiene que la perspectiva de los Derechos Humanos es repetitiva y circular, se prolonga hacia el infinito sin resolver nada, asegurando su inevitabilidad para asumir el problema de la cárcel. El método utilizado es el genealógico, como corresponde a la perspectiva adoptada, y se entiende como el proceso mediante el cual se interroga por el valor de los valores heredados. Como conclusión se propone que los Derechos Humanos no consiguen frenar la decadencia de la vida interna de la cárcel ni de la sociedad que reclama esta institución para su funcionamiento.

Palabras claves: Derechos Humanos, Genealogía, Cárcel, Derecho, Valores.

\section{Abstract}

This paper is part of the finished investigation The Bodies of Exception. Its purpose is to confront the perspective of genealogical reading with the perspective of human rights, around the problem of prison in Colombia. The central argument holds that the perspective of Human Rights is repetitive and circular, extending to infinity without solving anything, but ensuring its inevitability to take on the problem of prison. The method used is genealogical, as befits the perspective adopted, and is understood as the process by which it is questioned by the value of the inherited values. In conclusion, it is proposed that human rights fail to stop the decline of the internal life of the prison or the society that demands it to function.

Keywords: Human Rights; Genealogy; Prison; Law; Values.

\section{Introducción}

Nietzsche (2016a) plantea que la genealogía de la moral consiste en devolver los valores - prejuicios morales- al reino donde pertenecen, esto es, al reino del hombre y no de la divinidad. Es una falsa ilusión suponer que 
en octubre del 2014 y de cierre en febrero 2016 con el código INPR. 01. V1.

\section{Sobre los autores:}

1. Doctor en Educación,

Universidad de Antioquia.

Magíster en Psicología.

Estudios de pregrado en

psicología y filosofía.

Docente titular Universidad

de San Buenaventura

Medellín.

2. Estudiante de Maestría en Relaciones Internacionales, Universidad Autónoma Metropolitana. Abogada titulada.

3. Estudiante de Maestría en Ciencias de la Educación, Universidad de San

Buenaventura Medellín. Abogado titulado Docente de Cátedra Universidad Católica de Oriente. los valores tienen un origen (Ursprung) en Dios o que provienen de él. Esta ilusión también se expresa en la operación por la que se levanta el culto a una razón, causa oculta o esencia inaccesible de donde proceden las cosas. Para Nietzsche, los valores proceden de la historia de los seres humanos. No tienen otra procedencia. La genealogía se opone a dos simplificaciones metodológicas cuando se trabaja con materiales históricos. La primera, aquella que supone que la historia tiene un sentido supra histórico, es decir, su sentido -y se sabe que no lo tiene- se atribuye a Dios, la razón o el progreso, como si una fuerza superior la dirigiera hacia un destino irrepresentable, pero, en todo caso, capaz de determinar el curso de la historia. La segunda simplificación metodológica a la que se opone la genealogía es la de considerar al hombre como un ser pasivo dentro de un pasado muerto, tal vez irrecuperable que, no obstante, lo convierte en una víctima, incapaz de transformar su presente. De este modo, genealogía significa sacar a la luz, mostrar los valores heredados, no en todo su esplendor, sino en toda su miseria; mostrar la violencia y el engaño de donde proceden (Sánchez Santiago, 2017).

Expuesto lo anterior, se plantea lo siguiente: los Derechos Humanos representan, de por sí, valores evidentes, sugiere Hunt al afirmar que su verdad no es cuestionable. Sin embargo, siguiendo una perspectiva nietzscheana, cabe preguntar si, en vez de aceptar, sin más, la voluntad de verdad que inspira a los Derechos Humanos, se imaginara una voluntad de mentir que actúa como un narcótico que impide a los seres humanos despertar de su hechizo. Se supone que mientras los haya, hay esperanzas de un mundo mejor. Pero, inviértase esta suposición preguntando ¿y si todo eso fuera falso cabría albergar esperanzas? ¿A qué se reduce el mundo al descubrir que las esperanzas que los seres humanos albergan reciben su combustible de la falsedad? En la inmensa soledad en la que quedaría el hombre al descorrer el velo de los valores heredados, solo, consigo mismo, ¿qué oportunidades se abren para dar forma a una vida diferente? ¿Qué otras fuerzas podrían activarse para valorar de manera distinta? Por honor a la valentía y al coraje, el hombre habría de despertar y, como dirá Nietzsche (2014), por necesidad, se haría fuerte.

Este artículo hace parte de la investigación finalizada Los cuerpos de la excepción, su propósito estriba en oponer una perspectiva de lectura genealógica frente a la perspectiva de los Derechos Humanos, con respecto a la cárcel en Colombia. El problema, como se argumenta, consiste en que la cárcel en Colombia supera lo intolerable en múltiples registros; si por un lado no cumple su promesa de resocialización, tampoco cumple la de garantizar una sociedad más segura. Entretanto, la cárcel se afirma como un espacio, no solo de reorganización del crimen, sino de destrucción de un sinnúmero de vidas que, en el juego del poder, son sacrificadas para continuar jugando dicho juego sin considerar su costo. Por su parte, la perspectiva de Derechos Humanos, la prevaleciente en el momento de plantearse qué y cómo afrontar lo que ocurre en las cárceles en Colombia, es una perspectiva circular y repetitiva que diagnostica la violación de los Derechos y prescribe su restitución. Una perspectiva que no corrige realmente nada, pero que, justo por ello, conserva su vigencia inalterable en tanto performativamente reitera la necesidad de restituir los Derechos, sin considerar otras perspectivas de lectura crítica.

El método utilizado, como ya podrá inferirse, dimana de la perspectiva genealógica propuesta y se ubica en tres planos, a saber. En el plano epistemológico se trata de la destitución del sujeto (cartesiano y kantiano) como fundamento del conocimiento y del sentido. Para Foucault (2010), el sujeto no preexiste, sino que es producido a través de unas relaciones de poder que instituyen dominios específicos, tipos de 
saber y tipos de sujetos. Entre el sujeto y las cosas no hay una relación de identificación o de mutua necesidad, el sujeto del conocimiento y las cosas están constituidos por procesos históricos y relaciones transitorias. Adoptar un punto de vista externo, significa para Foucault poder emprender una historia política de la verdad. Como Nietzsche, no se trata de confirmar el origen incontaminado del sujeto y de las cosas, un origen donde la verdad se preserva pura y casta a la espera de su rescate, sino de mostrar las fuerzas enfrentadas, la violencia y el engaño de todo origen.

En el plano del saber histórico, Foucault se separa de la filosofía de la historia hegeliana y del historicismo. No reconoce ningún fin teleológico o sentido alguno de la historia. Es decir, la historia no conoce fines ni tiene sentido. En la historia lo que reina es la dispersión y el accidente, allí donde el historiador de oficio ve una necesidad natural de los acontecimientos, la genealogía advierte la arbitrariedad. En los acontecimientos no se encuentra nada que exija que las cosas sean como son, más bien, con paciencia, la genealogía muestra que, en todo caso, las cosas siempre podrían haber sido de otra manera y que detrás de ellas no hay esencia o verdad alguna, sino la voluntad de imponerse.

En el plano de la crítica, ya se indicó que la genealogía en Nietzsche se sitúa como crítica de los valores; en una perspectiva similar, Foucault, al explorar la historia de los valores que rigen, por ejemplo, el sistema penal y la sexualidad, no encuentra su verdad, esencia o universalidad, sino la singularidad, su construcción histórica.

A continuación, el artículo se organiza en cuatro partes. La primera, se titula Genealogía de los Derechos Humanos; la segunda Pequeño estado de la cuestión: la cárcel en Colombia; la tercera, Nietzsche y la violencia: la genealogía como perspectiva de lectura de los Derechos Humanos; finalmente, las conclusiones.

\section{Genealogía de los Derechos Humanos}

"La imagen de oleadas de aviones lanzando bombas sobre las ciudades y de figuras de pesadilla con máscaras antigás, trastabillando entre la niebla provocada por el gas tóxico, obsesionó a mi generación, proféticamente en el primer caso, erróneamente en el segundo"

Eric Hobsbawm (1998, p. 43).

Para Eric Hobsbawm (1998) el Siglo XX puede nombrarse como el Siglo del Horror. La Primera y Segunda Guerra Mundial, las revoluciones anticoloniales, la experimentación con armas nucleares y el genocidio como dispositivo de reorganización de las poblaciones, son suficientes criterios para suscribir tal afirmación. Resulta paradojal que el Siglo en el que más se habla del valor de la vida se explore con mayor éxito la capacidad de dar la muerte. Es decir, utilizando la terminología foucaultiana, la biopolítica, encargada de hacer vivir a través de copiosos censos, estadísticas y métodos de control, no se contradice con prácticas sistemáticas de exterminio.

En cierto modo, las dos guerras hacen patente, no el desvío de la razón, sino, más problemático, el cultivo de una razón instrumental que inevitablemente no tendrá otro destino que la guerra intensificada por su capacidad de destrucción. Las respuestas a las catástrofes históricas del Siglo XX no pueden ser más débiles: el regreso a la ética kantiana, el gesto indiferente que solo ve en dichas catástrofes anécdotas culturales de los Estados-nación directamente implicados o la actitud ingenua 
del que sostiene que su humanismo no ha sido destruido y que puede seguir en pie sin menoscabo de lo que ocurrido. En el registro de estas mismas respuestas puede incluirse la Declaración Universal de los Derechos Humanos, adoptada en 1948 por la Asamblea General de Naciones Unidas. Empero, por doquier se vociferan cantos en su nombre, tal vez, en el desespero y la parálisis política que produce no disponer de ningún otro recurso.

En este artículo se sostiene que los Derechos Humanos no son la corrección al problema del mal radical o moral y tampoco lo son del problema específico que se analiza en torno a la cárcel en Colombia. No pueden serlo por su misma historicidad. Al lector carente de perspectiva filosófica y que observa en ellos una voluntad genuina de corrección hay que oponerle una perspectiva nietzscheana: en el origen de las cosas, más exactos, en su emergencia, no se encuentra la pureza, la verdad o la esencia libre de toda mancha, sino el la violencia y el engaño. En este sentido, los Derechos Humanos también pueden interpretarse como un efecto de la mala consciencia descrita y analizada por Nietzsche (2016a) en De la genealogía de la moral. Los Derechos Humanos son el producto de la culpa que promete, de manera fallida, la reparación del daño.

En la perspectiva crítica de Hunt (2009), la verdad de los Derechos está confirmada -al menos en su formulación y a pesar de que no resulta claro cómo podría realizarse dicha verdad, en tanto que depende de un sinnúmero de confirmaciones que escapan a su misma esfera-. Pero, mírese bien, no es solo que los Derechos Humanos, hasta ahora, han permanecido como "papel mojado", por utilizar la expresión de Reyes Mate (2018), sino que, también, su historia está plagada de contradicciones. Váyase por partes.

En El contrato social de 1762, Rousseau, por primera vez, se refiere a los Derechos del Hombre, sin definir en qué consisten y para quiénes se reconocen. Por cierta deducción, esto conduce a pensar que son obvios y extensivos universalmente o, por el contrario, son Derechos destinados a una comunidad específica de hombres y, en esta medida, no hay razones para precisar a cuáles se destinan. Poco más de una década después, en concreto, el 4 de junio de 1776, se aprueba el Acta de Independencia de los Estados Unidos; en ella, Jefferson declara verdadero el que todo hombre es creado igual y está dotado por el Creador de ciertos derechos consustanciales, entre los que se encuentran la vida, la libertad y la lucha por la felicidad. A su vez, Condorcet, el importante representante de la llustración francesa, entiende los Derechos del Hombre como: derecho a la protección de la persona, derecho a la seguridad de la propiedad, derecho a la imparcialidad en la administración de la justicia y derecho a participar de la vida política y a elegir. Salta a la vista no los hombres que los derechos incluyen, sino aquellos que no alcanzan a ser reconocidos en la igualdad que el pensamiento ilustrado caracteriza. Más adelante, el 27 de agosto de 1789, diputados franceses adoptan varios artículos que se vienen discutiendo, con el título de Declaración de los Derechos del Hombre y del Ciudadano. Vale aclarar que esta adopción resulta clave para el reaseguramiento de los logros políticos alcanzados por la burguesía. De hecho, en La cuestión judía, Marx (2009) se esfuerza por mostrar la escisión que estos derechos producen entre el hombre y el ciudadano, considerando que la emancipación humana no puede ser igual a la incompleta e imperfecta emancipación política. Es decir, Marx advierte que la reconciliación del hombre consigo mismo no está en el plano del Derecho. 
El Acta de Independencia y la Declaración de los Derechos del Hombre y del Ciudadano, al igual que las reflexiones ilustradas, formalmente obturan el sistema de privilegios y desplazan la soberanía del rey o de príncipe hacia el Estado. Por lo tanto, un Estado soberano debe regirse por principios que otorgarán reconocimiento a todos los hombres libres. En este punto, es lícito suponer que hablar de hombres libres significa una duplicación de lo afirmado porque ser hombre (aquel que es sostenido antropológicamente por las instituciones culturales y preservado por las formas del Derecho), significa reconocer una voluntad libre. Solo es un ser humano aquel que puede afirmarse y ser afirmado en su libertad. En Estados así caracterizados, los judíos, los negros, los indios, los locos, los invertidos, los vagabundos y otras figuras históricas, quedan excluidos de la participación política, se les niega valor cultural alguno y su situación antropológica oscila en un limbo de contradicciones donde, por ejemplo, los excluidos no son propiamente animales, pero tampoco son seres humanos en el sentido que el Derecho reconoce la vida humana'. Esta cuestión es ampliamente planteada por Buck-Morss (2005) en Hegel y Haití. Uno de los elementos centrales del ensayo tiene que ver con lo paradójico que resulta el que los filósofos modernos, encabezados por Rousseau y Kant, enarbolaron las banderas de la libertad sin preocuparse por poner una palabra en nombre de la libertad de las colonias y de los esclavos. Tampoco dijeron nada en favor de la emancipación de los judíos de la opresión ejercida por la Europa cristiana.

En el presente, téngase por caso la manera cómo opera la política internacional de Estados Unidos creando campos de detención y de tortura a lo largo del planeta. Guantánamo, como explica Butler (2006), es apenas la expresión de un derecho que enaltece la vida, pero que, al mismo tiempo, construye espacios de suspensión del derecho, por lo que la vida queda suspendida en un limbo de contracciones que imposibilitan su protección. Esto permite inferir un cierto tipo de operaciones en las que se eleva a un tipo de hombre que, por definición, tendrá que reconocerse y protegerse por medio de marcos legales y distintas prácticas, ajenas al derecho, pero posibilitadas por este. Un esfuerzo por preservar las formas de vida humana que se considera necesario preservar. En el caso en cuestión es claro que las detenciones y las torturas llevadas a cabo en Guantánamo se justifican en nombre de la seguridad del ciudadano estadounidense y en defensa de su derecho a la vida. Esto no es extraño puesto que todo derecho requiere una cierta definición antropológica; aquí, la definición privilegiada es una que invoca que el hombre es capaz de juicios morales. Esto significa que hombre es aquel que, haciendo uso de su entendimiento, es capaz obrar conforme a una voluntad libre. Para el derecho internacional de Estados Unidos parece obvio que quienes atentan contra la existencia de sus ciudadanos y, mucho más, de su Estado, no son capaces de juicios morales y, por lo mismo, no pueden reconocerse en sentido pleno como seres humanos, pero, justo por eso, hay que hacer valer contra ellos los marcos legales disponibles y activar las prácticas que sean necesarias para garantizar el retorno a la normalidad, como la negación del derecho a la vida en algunos Estados Federados, mediante el recurso a la sentencia y la aplicación de la pena de muerte².

La definición de hombre que se está señalando se inscribe en el registro de la poderosa idea de autonomía producto del pensamiento ilustrado. Esta se caracteriza por dos capacidades. La primera, capacidad para razonar y, la segunda, capacidad

1. Los niños y las mujeres ocupan una posición ambigua, al declararse que son sujetos de protección especial, se los reconoce a través de una exclusión afirmativa.

2. Merece especial atención no solo las políticas de Rusia en contra de los homosexuales, dentro de las que se incluye detenciones preventivas o extrajudiciales y campos de concentración, también el pavoroso silencio de la comunidad internacional. 
para obrar de manera independiente. Así, por citar un ejemplo, Kant (1988) afirma que la ley moral requiere de un sujeto autónomo porque esta no se obedece siguiendo intereses particulares, sino porque la ley moral es buena en sí misma. Lo cual quiere decir que solo un hombre libre puede constituirse en sujeto moral. Ahora bien "Si los defensores de los derechos humanos universales, iguales y naturales excluían de forma automática algunas categorías de personas del ejercicio de esos derechos, ello era debido principalmente a que consideraban que no eran del todo capaces de tener autonomía moral" (Hunt, 2009, p. 27). En otras palabras, puede que formalmente se reconozca la autonomía como una facultad universal en la cual los seres humanos pueden encontrar su igualdad, pero, en la práctica, solo algunos pueden ejercerla desarrollando sus capacidades. Es probable que en este registro se entienda el por qué Kant sostiene que los seres humanos permanecen en estado de minoría de edad por pereza y cobardía, advirtiendo que, lo hacen la mayor parte de los hombres y, entre estos, la totalidad del "bello sexo"3.

Hunt (2009, p. 18) pregunta: “(...) si la igualdad de derechos es tan evidente, ¿por qué tuvo que hacerse esta aserción, y por qué se hizo solamente en momentos y lugares? ¿Cómo pueden los derechos humanos ser universales si no se reconocen universalmente?" A su vez, puede cuestionarse, si, no es, acaso, la universalidad declarada, el recurso a través del cual la exclusión de los excluidos se confirma y se ejerce por otros medios. Los Derechos Humanos, en su formulación, han requerido fundarse sobre tres tópicos: son naturales (inherentes al hombre), son iguales (los mismos para todos) y son universales (válidos en todo lugar y momento). Para ser más agudos, los Derechos no pueden cumplir la promesa de la universalidad porque su afirmación (o no) depende de la autonomía de los Estados -no todos los suscriben-; tampoco pueden ser iguales porque se administran de manera diferenciada -véase las Leyes de Núremberg que hacen imposible ser alemán y judío o la necesidad de preservar la blancura y la heterosexualidad de la "Nación americana" (Berlant, 2019)-; tampoco son naturales porque son Derechos en la cultura, no en la naturaleza. Expuestos de este modo, no hay evidencia de la universalidad, igualdad y naturalidad de los Derechos Humanos; como sostiene Hunt (2009, p. 25), lo que soporta la búsqueda de la evidencia de estos tres tópicos, se encuentra en el "(...) atractivo emocional" que despierta imaginarse respaldado y acogido por unos marcos que prometen preservar y sostener la vida.

En general, aquellos excluidos de la participación política, despojados de cualquier valor moral, cultural, racional e, incluso, estético, son lanzados al "espacio" vacilante que separa lo humano de lo no-humano. Foucault (2005) sostiene que, durante siglos, el hombre no fue otra cosa distinta de lo que era para Aristóteles, una criatura capaz actuación política. En la Modernidad, insiste Foucault, el hombre pone en duda su condición de criatura viviente en la política, incluso anulando dicha condición en nombre de la persona que la política consagra en el derecho. Cabe interrogar ¿qué tipo de hombre o, para precisarlo mejor, qué tipo de ser humano puede ser aquel que no goza de derechos políticos, sea porque estos le han sido sustraídos o porque, de plano, jamás se le han reconocido? ¿Qué tipo de violencia ontológica y antropológica se ejerce con la anulación de la criatura en nombre de la persona jurídica?.

3. Como ya se dijo, para Kant, los seres humanos persisten en un estado de minoría de edad por pereza y cobardía. Es decir, no hay algo constitutivo que los obligue a permanecer en dicho estado; son debilidades de la voluntad o fallos del carácter lo que los condicionan. En cualquier caso, la educación es el movimiento a través del cual los seres humanos pueden hacer uso de su libertad. Ahora bien, Kant no ofrece mayores argumentos, pero sostiene una curiosa diferenciación: la minoría de edad afecta a la mayor parte de los hombres y a todas las mujeres. Arriesgando una interpretación, podríamos decir que, no habiendo algo constitutivo que obligue la minoría de edad y dependiendo esta de la voluntad y del carácter, tenemos dos opciones. Una falsa y otra posible La primera en contra del argumento kantiano, sería que las mujeres tienen fallas constitutivas en la voluntad y el carácter; la segunda implicaría que, para la época, las mujeres están expuestas a mayores riesgos históricos si se trata de superar la minoría de edad, por lo tanto, persisten en rechazar la autonomía. 
En todo caso, como aclara Foucault (2006), no habría que culpar al positivismo por todo aquello que hoy puede juzgarse como una aberrante ignorancia o como una pérdida ontológica y antropológica de la que todavía no se puede calcular plenamente sus efectos. Más bien, hay que entender cómo las distintas racionalidades constituyen los objetos que se separan, analíticamente, para asignarles, a cada uno, su lugar. Los excluidos están separados de la vida política porque no pueden actuar de manera autónoma (presos, invertidos, vagabundos, entre otros), pero, a su vez, no actúan autónomamente en la vida política porque están excluidos.

Siguiendo a Foucault, podría agregarse: no se depende de la capacidad de la demostración empírica para mostrar al hombre, por todos lados, igual a sí mismo. Al contrario, en tanto la Modernidad no es la época del reino de Dios, sino la del reino del hombre en el mundo, esto es, la época en la que el hombre se toma a sí mismo como referente de su formación, entonces la humanidad no se forma recurriendo a fuentes empíricas o positivas, sino mediante complejos procedimientos de implantación que dividen, clasifican, separan y, al tiempo, homogenizan. A propósito de las preguntas formuladas, lo que se está afirmando es que la Modernidad es una máquina capaz de transfigurar a la criatura humana en un sujeto de derecho (persona), despojándola de cualquier otra existencia. Al parecer, el hombre no es más que lo que el derecho decida que debe ser, porque solo en el derecho encuentra los marcos para su preservación y sostén. En términos de Agamben (2006), esto podría interpretarse como una incesante máquina antropológica que, en el pavoroso juego de la verdad, decide lo humano y lo no-humano.

Los Derechos del Hombre y del Ciudadano, los Derechos del Género Humano o los Derechos Humanos, históricamente, son el reconocimiento de la separación entre lo divino, lo humano y lo animal, reconocimiento que abandona a Dios y produce lo humano como superior y dotado de una dignidad nunca extensiva hacia lo no-humano. En síntesis, los Derechos no son la afirmación de la igualdad política o formal y, mucho menos, la igualdad sustantiva entre los seres humanos. Los oprimidos, como lo diagnosticó Benjamin (1999), diagnóstico que Agamben (2007) continúa en su ensayo Infancia e historia, permanecen en un estado de excepción que niega, confisca o desplaza hacia un porvenir incierto, los derechos. Probablemente, no hay falla en los Derechos Humanos porque, constitutivamente, no fueron concebidos para representar la experiencia absoluta de los seres humanos. Antes bien, los fallos que conducen al permanente estado de excepción antropológico, no habría que buscarlos en la no realización de los Derechos, sino en la insidiosa voluntad ontológica y antropológica que no cesa de imaginar lo humano y de producirlo en la devastación fragmentaria que lo separa de lo no-humano. Insístase, tal vez, los fallos estén en la voluntad que funda y refunda un proyecto moderno jamás alcanzado: perfeccionar al hombre o alcanzar una humanidad conforme a su ideal de perfección. Como sostiene Piñeres Sus (2016), todo ideal es una forma de hacer violencia a lo real.

En esta dirección, y propósito de la Modernidad nacional, Muñoz Gaviria (2005) afirma que esta en Colombia no se entiende sin el análisis de la apropiación del evolucionismo social realizada por intelectuales como Miguel Jiménez López, Luis López de Mesa, Martín Camacho, Laurentino Muñoz y Jorge Bejarano, entre otros. Las ideas de Spencer sirven de base para desarrollar el diagnóstico y los planes de intervención de un pueblo imaginado, física, psicológica y moralmente, deficitario. La Modernidad nacional resulta, pues, indisociable de fuertes criterios de diferenciación social. Estos criterios no solamente responden a la clase, sino que también reclaman la producción de la diferencia racial: el pueblo, además de enfermo, inadecuado 
y peligroso, es racialmente infecto. Esta perspectiva sirve para plantear que en Colombia la Modernidad (re)inaugura la pregunta por el hombre genérico convirtiendo a los seres humanos reales en objeto de una desvalorización endémica. En esto reside su voluntad de corrección y de exterminio. Para Zuleta Pardo (2010), esa orientación pedagógica y paroxística hacia la perfectibilidad, esa admiración por lo que no se es y el desprecio por lo que se es, autoriza una moral de la crueldad que se sirve del conocimiento producido en esa intersección (admiración y desprecio) para ejecutar los más horrorosos planes de corrección y exterminio que el país ha conocido.

Aunado a lo anterior, la Modernidad se mueve a través de mecanismos de discontinuidad (diferenciación con respecto al pasado) y de desanclaje (integración global de las sociedades modernas). En su análisis, Muñoz (2005) sigue a Giddens señalando que dichos mecanismos implican, por necesidad, la creación de instituciones como la escuela y la homogenización de señales simbólicas como la circulación del dinero y la administración del tiempo y el espacio. A propósito de la cárcel hay que señalar que el desmonte de las políticas de bienestar y el acelerado proceso de privatización no solamente supone un cierre de la política con respecto a los principios de justicia, igualdad y libertad, sino que la constituye como esa institución sin la cual no será posible realizar plenamente dicho cierre. Es decir, la Modernidad tardía y el capitalismo moderno requieren de la cárcel su más productivo funcionamiento para continuar dando forma al orden social.

Siguiendo a Dávila Londoño (2015), cabe acotar que la idea de orden social invoca a un tipo de ordenamiento interno que regula los fenómenos sociales; pero, si se acepta la existencia de dicho orden, implícitamente se exige que solo este pueda existir. En otras palabras, la defensa del orden social (como si se dependiera de manera inexorable de instintos gregarios) es la negación de las distintas fuerzas agonistas que luchan por hacerse preeminentes y la voluntad de imponerse anulando el enfrentamiento. En este sentido, la cárcel es una institución que amenaza y procura disuadir a todos aquellos que interrogan el orden social impuesto. Mientras los Derechos Humanos no actúen para combatir dicho orden, lo que significa combatir la razón instrumental y el capitalismo, en la práctica no podrán significar nada en favor de la destrucción que la cárcel opera sobre los seres humanos desechados.

\section{Pequeño estado de la cuestión: la cárcel en Colombia}

Para avanzar con el problema planteado en este artículo, se recurre a un pequeño estado de la cuestión, en el que se exponen los principales resultados de investigación que se adentran en la situación carcelaria en Colombia discutiendo los Derechos Humanos.

En Drama humano en los centros penitenciarios y carcelarios de Colombia, Ruiz y Serrano (2013), analizan las condiciones de hacinamiento en las que se encuentra la población carcelaria y penitenciaria de Colombia. Se plantea que el hacinamiento en su condición de causa provoca la vulneración de la dignidad humana, dificulta el cumplimiento de los estándares de salubridad e higiene, pone en riesgo la salud física y psíquica de los reclusos, genera carencia en la prestación de servicios (asistencia médica, deporte, alimentación sana, recreación, educación) y favorece la proliferación de la delincuencia y la violencia. De la misma forma, el hacinamiento como efecto es la consecuencia de una política criminal inapropiada que tiene un enfoque reactivo más que preventivo, es decir, una política criminal que no toma en 
cuenta una política social que garantice los estándares mínimos de bienestar (salud, educación, vivienda e ingresos).

La precariedad en la que se encuentran las instalaciones carcelarias, hace que no existan espacios comunes destinados a la realización de actividades con fines educativos, o que, habiéndolos, se utilicen para fines diferentes. Este tipo de actividades que, por lo general se consideran claves para la resocialización, descansan en el criterio particular de los entes administrativos y de vigilancia de la cárcel. Es decir, si en el papel se garantizan, en la práctica puede ocurrir cualquier cosa. Dentro de lo identificado, también está que hay población que no tiene ni siquiera asignada una celda, en ocasiones duermen en baños y pasillos. Por otra parte, los reclusos no están siendo clasificados según el tipo de delito en que incurrieron y el estado del proceso en que se encuentran, lo que vulnera la presunción de inocencia, pues, se supone, no es lo mismo estar en la cárcel con una medida de aseguramiento que estar en la cárcel con condenado. Estas carencias y problemas que se originan por el hacinamiento dificultan procesos de resocialización. Los autores concluyen que para evitar el hacinamiento la cárceles y penitenciarias deben atender criterios de habitabilidad tales como volumen del aire, superficie mínima, alumbrado (luz natural y artificial), calefacción, ventilación, limpieza, asistencia médica, instalaciones sanitarias y de aseo, suministro de agua potable y evacuación de aguas residuales. Es decir, para Ruiz y Serrano el problema no es la cárcel sino la manera cómo se administra. Esta actitud pudorosa parece advertir un futuro prometedor para la cárcel si se acompaña de los debidos procesos, como si esta pudiera escapar a la bajeza y la mezquindad que la precede y sin las que no puede funcionar.

Huertas, Suárez y Morales (2014) en Derechos humanos en la prisión en Colombia, indican los principales Derechos Humanos que se afectan en la prisión a través de un análisis de los informes del Instituto Nacional Penitenciario y Carcelario- INPEC. En este trabajo se plantea que el populismo punitivo y la criminología mediática son los criterios que actualmente están orientando la política criminal en Colombia; por esto es común que se asocie la política criminal con tintes democráticos, pues son las masas las que piden la creación de tipos penales, eso sí, después de que se le trasmiten sentimientos de angustia e inseguridad. Siguiendo con el argumento anterior, la estrategia para quienes aspiran a cargos de elección popular es garantizar la seguridad ciudadana mediante el establecimiento de más tipos penales, penas más altas y más represión para quienes cometen conductas desviadas. La dirección de la política criminal entonces se encamina a mejorar la percepción de seguridad por esos medios, aunque estos no resulten efectivos. La estrategia de prevención del delito basada en la imposición de medidas de aseguramiento en los penales es implementada por el sistema judicial para mostrar eficiencia y evitar reclamos de la sociedad, los medios de comunicación y el poder político. Los autores manifiestan que es necesario replantear la política criminal con enfoques que reduzcan el uso de la prisión y den paso a otras alternativas, pues el número actual de población detenida de manera preventiva es exagerado y aumenta considerablemente la población carcelaria.

La pena está cumpliendo un papel vindicativo y retributivo más que de reinserción, los castigos a los que son sometidos los presos dan cuenta de ello. La limitación del acceso al agua propaga enfermedades y epidemias, hasta seis detenidos deben dormir en una misma celda, hay restricciones para recibir visitas familiares (por la distancia entre el centro carcelario y la vivienda y por la política del pico y placa la cual establece que los presos solo pueden recibir visitas cada quince días), 
las celdas se compran y se venden; los homosexuales y los transexuales son explotados de múltiples formas; y la satisfacción de necesidades mínimas es asumida por el mercado negro. El porcentaje de reincidencia indica que la política criminal no está buscando la vinculación del sujeto a la sociedad, sino que, por el contrario, está multiplicando las conductas delictivas: del total de personas privadas de la libertad a cargo del INPEC el 11,4\% son reincidentes (INPEC, 2019).

El trabajo de Huertas (2015) Sistema penal y hacinamiento carcelario: análisis al estado de cosas inconstitucionales en las prisiones colombianas, cuestiona que, aunque está constituida como un Estado Social de Derecho, Colombia no garantiza ni protege los derechos fundamentales de las personas que habitan el territorio. Esta obligación es imperante especialmente desde el año 1992, con la vigencia de la Constitución Política de 1991, donde se empieza a percibir con mayor claridad la problemática de las violaciones a los derechos fundamentales de las personas recluidas en las prisiones. Se puede afirmar que con la sentencia T-153 de 1998 de la Corte Constitucional colombiana, que declara el Estado de Cosas Inconstitucionales (ECI), se logra un avance en la garantía de los derechos fundamentales al reconocer su permanente violación en las cárceles y al ordenar al Estado tomar medidas tendientes a la recuperación de los Derechos Humanos. Sin embargo, a pesar de este logro, la falta de garantías constitucionales, en conexión con el problema de la sobrepoblación carcelaria, conlleva a la corrupción y a la necesidad de formación de estructuras ilegales, de manera alterna, en las cuales se negocian y se comercian bienes básicos insuficientes que el Estado no garantiza.

La misma sentencia propone que los jueces en Colombia busquen alternativas de castigo para los condenados o que implementen sanciones que correspondan al delito que se penaliza. A su vez, se prescribe un trato humanitario desde el momento en el que se concreta la privación de la libertad como la pena. De lo contrario se estaría afirmando a la prisión como la forma general de castigo. El Estado debe garantizar una prevención especial positiva, es decir, debe buscar la resocialización del condenado, preservando su autonomía y dignidad. El condenado continúa en una relación especial de sujeción con el Estado, la cual no le quita su calidad de sujeto de derechos, en la misma medida, se debe priorizar una especial protección de los derechos fundamentales, los cuales no puede ser suprimidos ni limitados porque estos tienen una relación intrínseca con el principio de dignidad humana. Por esto, el Estado colombiano debe plantear políticas públicas que sean concordantes, razonables y proporcionales con relación a las políticas criminales y carcelarias.

Arenas y Cerezo (2016) en su artículo Realidad penitenciaria en Colombia: la necesidad de una nueva política criminal, analizan las consecuencias del hacinamiento penitenciario, los derechos fundamentales vulnerados y las condiciones de vida básicas en prisión; también examinan los problemas en infraestructura carcelaria, el tipo de población carcelaria, el perfil de los reclusos y el tratamiento penitenciario. Las condiciones deshumanizantes en las que se encuentran la mayoría de los internos en Colombia muestran la responsabilidad del Estado como principal garante de los derechos fundamentales. Sin embargo, la respuesta de los poderes públicos hasta ahora ha sido acudir a una política criminal que lucha contra la delincuencia solo con la imposición y creación extensiva de penas privativas de la libertad a los delitos que son reiterativos. Lo anterior indica que el Estado está olvidando los sectores más desfavorecidos de la sociedad donde son evidentes las estructuras de la desigualdad que generan pobreza y marginación social, lo que se relaciona con mayores 
tasas de delincuencia. En resumen, el Estado implementa condenas y no oportunidades sociales.

Debido a las exigencias y sanciones al Estado colombiano, por parte de organismos nacionales e internacionales, garantes de Derechos Humanos, se reformó el Código Penitenciario y Carcelario y el Código Penal con la Ley 1709 de 2014. Con esta modificación se logra un avance en materia de resocialización como principal objetivo de las penas de prisión, mejoras en las condiciones sanitarias de los centros de reclusión, aplicación de penas sustitutivas cuando haya lugar, flexibilización de medidas privativas de libertad, entre otras medidas que siguen consignadas en la norma y no en la realidad social. La política criminal sobre la seguridad ciudadana debe tratar de conciliar con los colectivos más pobres y dejar de perpetuar la criminalización de los estratos sociales más bajos, optando por no tipificar ni aumentar las penas relacionadas con los estados de necesidad de colectivos desfavorecidos. Lo que implica, además, trabajar intensamente por mejorar las condiciones sociales, mejorar las posibilidades para la educación, mejorar las políticas públicas e implementar una política criminal y carcelaria que sea coherente y razonable con las necesidades de los condenados, alternativas en las penas privativas de libertad y cambiar la actitud de la sociedad hacia el delincuente. Ahora bien, como podrá deducirse, todos estos avances son formales.

En el 2016, Ossa López publica La cárcel en Colombia. Espacio para la venganza y la reincidencia. Este estudio centra sus conclusiones, como puede deducirse, en el problema de la reincidencia. Desde un comienzo se declara que la cárcel no es un espacio para la resocialización puesto que no hay nada en ella que permita que los presos puedan construir unas condiciones diferentes a las que conducen otra vez a la criminalidad. A juicio de la investigadora, las oportunidades y la educación resultan claves a la hora de considerar la posibilidad de disminuir la delincuencia. Más que reclamar la construcción de más centros carcelarios o de reformar el código penal, la política tendría que adoptar una postura preventiva. Sin embargo, su planteamiento se anula por sí solo en el momento en el que, tratando de no adoptar una postura construccionista con respecto a la criminalidad, por lo cual esta estaría ligada a las condiciones sociales y materiales más que a una determinación particular de algunos individuos, sostiene que, en todo caso, en la reincidencia son importantes “(...) los elementos inherentes al recluso, como son sus características individuales y su conducta habitual, propia de su estructura psicológica que, independientemente de los factores externos, lo condicionan llevándolo de una u otra forma a delinquir" (Ossa López, 2016, p. 154-155). En el fondo, y por más que juegue a incorporar una lectura compleja del delito, el recurso a la psicología termina por derivar que para la criminalidad se nace. Ahora bien, lo que Ossa López no proporciona es la explicación de por qué la criminalidad no se distribuye aleatoriamente entre las clases sociales o por qué se le persigue con mayor furor en los más desfavorecidos.

Utilizando las categorías del black feminism y la necropolitíca, Bello y Parra (2016) en Cárceles de la muerte: necropolítica y sistema carcelario en Colombia, realizan una crítica a los informes de Derechos Humanos en las cárceles en Colombia. Los autores encuentran que la política criminal es selectiva y está afectada, principalmente, por matrices interseccionales que vinculan raza, clase, género, sexualidad y edad. La cárcel no constituye grupos homogéneos; al contrario, algunos no solo deben comparecer ante el castigo de la privación de la libertad, sino que, también, son expuestos a un espacio de muerte como tecnología disciplinaria sistemática de la violencia y el terror. A esto se denomina "complejo industrial carcelario". Este complejo fue 
trasplantado a finales del siglo XX con la articulación de nuevas arquitecturas carcelarias y regímenes disciplinarios represivos que destruyen la privacidad y autonomía corporal de los presos despojándolos de su sentido del yo. Nótese, por ejemplo, el efecto desigualdad de destrucción que la cárcel introduce entre los presos, siendo, probablemente, los hombres homosexuales los que encaran mayores riesgos.

El nuevo sistema económico neoliberal se vale del fortalecimiento del aparato punitivo como medio para controlar grupos sociales marginados y estigmatizados por el mercado. De esta manera, la cárcel es protagonista de la globalización. El status quo instalado se defiende a través de la policía, el encarcelamiento y el sistema judicial, revictimizando de esta manera a los grupos sociales más vulnerables. La cárcel se configura como el espacio donde los derechos se suspenden y los cuerpos se reducen a cosas: los presos son expuestos a enfermedad, aislamiento, desatención médica, mala alimentación, abusos sexuales, angustia, daño físico y mental, muerte biológica y social. La población carcelaria no reconoce sujetos sino objetivos militares.

En El sistema penitenciario y carcelario en Colombia: continuidades y discontinuidades foucaultianas, Arrieta Burgos (2017) señala que el sistema carcelario en Colombia continúa obsesionado con el castigo del cuerpo mediante la práctica del suplicio y no hay una resocialización como finalidad de la pena. Las cárceles tienen un panorama, cada vez más deprimente y lamentable, de condiciones que van en contra de los Derechos Humanos. El funcionamiento de la prisión fracasa porque en vez de corregir se ha convertido en un mecanismo que solidifica la delincuencia y facilita la formación de verdaderas repúblicas independientes donde el orden social está controlado por el negocio de las estructuras plurales e informales de poder, que reemplazan al Estado para suplir sus abandonos. Esto permite que el sistema penitenciario en Colombia se haya configurado no solo en un negocio criminal, sino también en un reservorio de prácticas políticas populistas. En tanto que el Estado permanezca enfocado en las medidas, y no en los derechos, se perpetuarán los incumplimientos en materia penitenciaria y carcelaria.

Arieta Burgos analiza las sentencias de la Corte Constitucional donde se declara y se da seguimiento al Estado de Cosas Inconstitucionales (ECI) en las cárceles. La sentencia T-153 de 1998 trata de dar un mejor manejo a las cárceles en Colombia, pero deja dificultades como las estructuras penitenciarias, el cierre masivo de prisiones y el deficitario seguimiento por parte de la Corte Constitucional. La Sentencia T-388 de 2013 se enfrenta a los mismos problemas al acoger políticas parecidas a la sentencia anterior, pues, aunque la Corte Constitucional analiza el estado de cosas contrarias a la legislación vigente, las personas no adquieren un derecho constitucional subjetivo a ser excarcelados, por ejemplo. Con estos antecedentes surge la sentencia T-762 de 2015 que aspira a ofrecer un referente más racional con respecto a los diagnósticos y sus soluciones y al seguimiento de la misma sentencia, además de una intención clara dirigida a la recuperación de derechos fundamentales. Ahora bien, los procesos son muy frágiles en materia penitenciaria y carcelaria para el sostenimiento de una política pública dirigida a la resocialización.

Este pequeño estado de la cuestión deja varias cosas al descubierto. La situación de los centros carcelarios en Colombia es intolerable, no solo funciona como una institución que destruye lo que promete resocializar, sino que la misma cárcel se configura en un fortín que los poderes políticos y sociales se disputa. Su estado endémico, su intensificación de la violencia y de las formas de reducción antropológica, 
lejos de significar un desvío de los propósitos, es la realización de lo que debe ser la cárcel para cumplir lo que en verdad se propone: destruir a los ya destruidos. En efecto, esa economía de la destrucción es la que, paradójicamente, robustece los poderes políticos y sociales. Por otra parte, a pesar de lo intolerable, los artículos revisados, en general, no ponen en cuestión la existencia de la cárcel, sino que la imaginan mejorada y sirviendo plenamente a la sociedad en unas condiciones aceptables que se consideran humanas.

Debido a lo anterior, la perspectiva de los Derechos Humanos, tan reclamada por los investigadores expertos en el tema de la cárcel, introduce interpretaciones de alcance repetitivo y circular. Se diagnostica que en la cárcel se violan los Derechos Humanos y la respuesta a dicha violación es su restitución. Cabe interrogarse si, en cierto sentido, insistir en un enfoque repetitivo y circular, más que horadar el estado de cosas que se cuestiona, resulta útil para preservarlo en tanto que lo expone como inevitable por su fuerza performativa. Hablar de Derechos Humanos y de su violación hoy por hoy se ha convertido en un lugar común que permite la toma de posiciones por parte de académicos, investigadores, organismos no gubernamentales y políticos de oficio, posiciones que se fortalecen a sí mismas en la repetición del ciclo infernal de lo que denuncian y que dicen rechazar. Lo que aquí se señala es la necesidad de advertir perspectivas de lectura distintas que permitan enfrentar, de otra manera, la vergüenza de una institución como la cárcel. Como dirá Foucault (2012), la cuestión no es averiguar cómo mejorar la cárcel, sino interrogar qué tipo de sociedad es aquella que la requiere para su funcionamiento.

\section{Nietzsche y la violencia: la genealogía como perspectiva de lectura de los Derechos Humanos}

Nietzsche (2016a) sostiene que el hombre es el único animal que se hace promesas y que convierte las costumbres en moralidad. Hay un primer vínculo entre las unas y las otras, este se refiere a que los valores morales son promesas que el hombre se hace a sí mismo. No obstante, cuando estas son contrarias a los instintos, el hombre se retrae, olvida. Así surge un segundo vínculo entre las costumbres y las promesas, en la medida en que la moralidad no logra por sí sola asegurar a estas últimas, entonces crea el Derecho que funciona como una amenaza para obligar su cumplimiento. Esto es, el Derecho es una nemotécnica del dolor que fija las promesas en la memoria para que el hombre no pueda escapar a su cumplimiento sin ser perseguido por la sombra de la pena. "Las leyes penales son para el filósofo, por así decirlo, la inscripción y transcripción de la moral. El derecho penal se vuelve así, en un aparato inhibidor de los instintos, para ser constantemente recordados en su negación. Como tal, el derecho penal para Nietzsche sirve para hacer más vívida la conciencia de la culpa (moral)" (Carrasco Jiménez, 2008, p. 6).

Para Elhart (2018) las formas jurídicas y el mismo proceso civilizatorio, aunque restrinja las posibilidades de los instintos, sí permite el uso de ciertas libertades y consagra la posibilidad de la vida para los seres humanos. Por eso, a pesar de la sagacidad del pensamiento de Nietzsche y de toda su capacidad para desnudar los mitos, no se puede aceptar sus consecuencias. Nietzsche desbroza una perspectiva evolutiva sobre el desarrollo del hombre y una confianza en que en el despliegue sin culpas, castigos o limitaciones de los instintos conducirá a su superación; es decir, la perspectiva de Nietzsche no es otra cosa que la glorificación de la violencia, el caos y la destrucción. El argumento de Elhart, a través del que se rechaza o, al menos se incita a rechazar, el pensamiento de Nietzsche en sus consecuencias, reposa en dos 
operaciones. La primera es la confusión por la cual se imagina al señor con el monopolio de las fuerzas y al esclavo como el carente de las mismas. Antes que Elhart (2018), Kostenwein (2015) demuestra que entre el señorío y la debilidad la diferencia es de cualidad y no de cantidad; así, tanto el señor como el esclavo disponen de fuerzas y, por lo tanto, la capacidad de lucha no es ajena a ninguna de las dos figuras. Sin embargo, el señor domina y el esclavo es dominado porque mientras el primero reclama un gobierno de sí mismo, el segundo se subordina al dictado de los otros. El señor usa sus fuerzas para crear valores, el esclavo las usa para obedecer. En específico: "por dominante no debemos entender aquí al que domina, sino al que se domina. Y por dominado no debemos entender aquel sojuzgado por otros, sino aquel que se somete principalmente como producto de las opiniones instauradas, las que a su vez le impiden tener que preguntarse acerca de lo realmente valioso y singular de su propia experiencia; en definitiva, a quien se subordina pudiendo no hacerlo" (Kostenwein, 2015, p. 240). La segunda operación es una ingenuidad desde la que el pensamiento de Nietzsche se intenta capturar mostrando su agudeza y perspicacia, pero oponiéndolo a una mirada, siempre atenuada, del costo que ha traído para el hombre la civilización y sus procesos de domesticación. Elhart reconoce la fuerza del argumento de Nietzsche, pero se decanta por rechazarlo en sus consecuencias porque los riesgos implican la instauración de nuevos valores. Nietzsche es peligroso porque interroga por el valor de lo que valoramos y exige el coraje y la valentía para inventar formas distintas de valoración.

Contrario al planteamiento de Elhart (2018), Nietzsche no es una apologeta de la violencia, aunque tampoco puede relacionarse con una visión romántica del hombre en estado de naturaleza, como aparece en Rousseau, ni con el realismo político de Maquiavelo o el formalismo de Kant; de hecho, sus libros ofrecen una rica alternativa intelectual para pensar los entresijos y las vacilaciones con las que se interpreta la violencia. Podría decirse que en Nietzsche se encuentra una meditación elegante sobre ella. En último término, Nietzsche remite su reflexión sobre la violencia a los procesos mediante los cuales el hombre se ha "civilizado"; los valores platónicos, el arte, la religión y la ciencia, podría decirse, son instintos civilizadores. Esto es, civilizar significa domesticar. El contenido de la domesticación consiste el debilitamiento de las fuerzas activas del hombre (por lo cual se declara que las normas deben remplazar la fuerza) y en canjear la libertad por instintos gregarios (que adoptan su forma básica en el contrato).

Enfrentados al problema de la cárcel, el enfoque nietzscheano resulta útil para pensar la libertad más que la igualdad. Lemm (2012) sostiene que esta es una elaboración que surge del enfrentamiento entre la civilización y la cultura, y no un regalo de las instituciones políticas. Mientras la civilización amenaza con que la libertad solo es posible en el marco de sus distintos sistemas políticos, no pocas veces contradictorios -he aquí lo sospechoso-, para Nietzsche (2016b), la libertad es, en realidad, una continua e inquietante elaboración de lo que se es, en una apertura radical hacia la diferencia. En Nietzsche, esto corresponde a la cultura y sus fuerzas creadoras. Así, la búsqueda de capturar la libertad en la forma de un derecho universal igualitario, fracasa estrepitosamente. La libertad no se entrega sin matices, tampoco se entrega a la tozudez que la declara abierta para todos sin ningún tipo de experimento del hombre consigo mismo. Tal vez por ello, la libertad como un derecho parece condenada a ser un mero formalismo. "El aristocratismo en Nietzsche, entonces, asume la figura de la responsabilidad de someter nuestros procesos democráticos de institucionalización a una crítica permanente y radical" (Lemm, 2012, p. 22). 
Se ha dicho que la perspectiva de los Derechos Humanos, perspectiva prevaleciente en la lectura del problema carcelario en Colombia, es insuficiente para comprender los alcances de un problema que no da muestras de solución alguna. Por oposición, se propone una perspectiva de lectura genealógica que plantea que la cárcel responde a dos tipos de violencia, a saber, fundacional y social. Ambos tipos se pueden leer desde la perspectiva nietzscheana en estos términos: la violencia fundacional es aquella por la cual un grupo, para conservar su homogeneidad, su sentido del "nosotros", busca destruir a los "otros" o su afuera (representado en términos de raza, religión, sexualidad o nación, por ejemplo). La violencia fundacional defiende el derecho a castigar. Resulta pues paradigmático que el que castiga imagina que el castigo hará mejor al castigado -mejor para sus propios fines-. Sin embargo, qué ocurre cuando se descubre que no hay un derecho ingenuo, tampoco ningún derecho natural, puesto que todo derecho es una invención que, si acaso, responde a costumbres también inventadas y que, en cualquier caso, siempre podrían haber sido otras o, simplemente, no haber sido o desaparecer. La pena en el Derecho, afirma Nietzsche, no dimana de ninguna intención previa, esta se añade para proteger de la mala conciencia a los que defienden su derecho a castigar. Por su parte, la violencia social se caracteriza por el recurso a la tortura, la crueldad o el asesinato como el mecanismo mediante el cual se repite, sin mediación simbólica, experiencias originales y absolutas de dominación (como queda expresado en los linchamientos de los seres, monstruosamente imaginados, que amenazan valores tan hipócritas como la propiedad y el pudor sexual). El lector puede percibirlo, no hay oposición entre estos dos tipos de violencia, al contrario, la evidencia muestra que son complementarios y se alimentan recíprocamente; los renovados códigos de la policía son expresión palpable de esta complementariedad.

Habida cuenta de todo lo anterior, tendría que traducirse el proceso civilizatorio como un violento e incesante trabajo en contra de la cultura. A su vez, como un imperioso esfuerzo por domesticar los instintos. Por lo que, como sostiene Sánchez Meca (2000, p. 221), Nietzsche propone su propia y radical interpretación en torno a "(...) deshumanizar la naturaleza para renaturalizar al hombre". Deshumanizar la naturaleza será el trabajo por el cual se rechaza que el mundo, las cosas y el hombre tienen sentido en sí. Tampoco se puede ceder a la tentación de conceder que la naturaleza evoluciona conforme a un plan racional. No hay, pues, ningún plan que tenga por propósito mejorar o perfeccionar la naturaleza o al hombre. Es decir, la genealogía enseña a descubrir el engaño que se levanta toda vez que se invoca los mandatos naturales o la naturaleza humana y el derecho que a esta corresponde. La providencia kantiana, por lo tanto, miente en aquello de que el destino del hombre es humanizarse conforme a un plan de la naturaleza. De Kant se desprende que humanizarse es una obligación moral. Pero, como advierte Nietzsche, toda moral solo es una perspectiva. Por su parte, renaturalizar al hombre significa sanear sus instintos; si la domesticación lo ha hecho débil, enfermo y fanático, si los valores heredados a los que se aferra son síntomas de una enfermedad -la decadencia-, sanear implica la destrucción de los efectos narcóticos de la domesticación y de los valores heredados. La renaturalización exige confianza en las fuerzas creativas, instintivas y vitales del hombre. Exige confiar en aquello que la filosofía platónica, el cristianismo, el arte ascético y la ciencia moderna han sacrificado - la vida, el cuerpo, los instintos y las pasiones-, prometiendo un mundo más allá de este mundo.

Nietzsche, por lo tanto, se propone, no como el fin de la metafísica, sino como la cúspide de un pensamiento que ofrece otras posibilidades interpretativas que reclaman una nueva cultura capaz de crear valores diferentes, los valores de los señores. La 
función del filósofo, pues, no es la búsqueda de la verdad (como en la metafísica) o la producción del conocimiento (como en la epistemología), sino mostrar la vida, el cuerpo, los instintos y las pasiones destruidos, en un esfuerzo por abrir el espacio para que otras interpretaciones puedan ser posibles. "Siendo evidente que la prisión no se sostiene por sus virtudes, y que para debilitarla es insuficiente con denunciar las ignominias o descuidos que provoca, quizá nos incumba crear nuevas formas de percepción" (Kostenwein, 2015, p. 248).

\section{Conclusiones}

Deleuze (2006) afirma con decisión que los Derechos Humanos no son la solución a lo intolerable del Estado moderno, porque estos Derechos no sacrificarán las "delicias" que, por ejemplo, el capitalismo y el liberalismo promete a los Estados y de las cuales participan los mismos Derechos. No hay estado que "(...) no esté comprometido con la fabricación de miseria humana" (Deleuze, 2006, p. 270) y con el menoscabo de la vida. Se habla, pues, no para celebrar el valor de los Derechos, sino en nombre de una vida lograda, la vida que falta al hombre.

Vida aquí no remite a un Derecho natural; como sostiene Foucault (1999), antes que cualquier Derecho de este tipo o de cualquier otro, está el movimiento que no acepta más lo intolerable, el movimiento a través del cual los seres humanos se sublevan, el movimiento que rechaza que la vida sea objeto de canje. Eventualmente, se podrá cuestionar un vitalismo, ajeno a Foucault, que se sirve de argumentos foucaultianos. Al respecto, se puede precisar que en el pensador francés se advierte un peculiar vitalismo que lo une a Nietzsche. En primer momento, Foucault avanza la "muerte de Dios", pronunciada por Nietzsche, con la "muerte del hombre", en un trabajo crítico contra la episteme y en un esfuerzo por producir nuevas fuerzas capaces de sustraerse al saber y resistir los embates del poder. Seguidamente, de las relaciones entre esas fuerzas se despliega una analítica sobre la vida y la muerte que involucra la pregunta por la finitud y los límites del pensamiento. Por último, la subjetivación que Foucault propone, subjetivación que no se trata de relaciones de identidad sino de intensidades, vuelve y lo une a Nietzsche en una concepción estética de la vida -y la muerte-, donde se impone la necesidad de renovar las fuerzas vitales creando otros estilos de vida (Deleuze, 2006). Lo que se está señalando es que la promesa de los Derechos Humanos no puede realizarse, lo suyo es el desplazamiento permanente de la promesa en torno a un tiempo utópico donde la humanidad habrá reconciliarse consigo misma. Renovar las fuerzas vitales y la creación de estilos de vida pasa por rechazar la gestión, administración y gobierno de la vida en nombre de fines superiores cuando lo que está en juego es la devastación de las posibilidades de dar forma a una vida lograda.

Para cerrar, váyase al Zaratustra (2016c) de Nietzsche. En tono profético, este afirma que los declamadores de la igualdad lo son por impotencia. Con palabras virtuosas enmascaran secretas y tiránicas aspiraciones de dominación. A cada valor heredado hay que interrogarlo por su valor. Esto es, qué hace que un valor tenga valor. Nietzsche exige que los señores sepan distinguir lo que los hace más fuertes y lo que los debilita, exige que aprendan a distinguir entre las cosas y las acciones que fortalecen la vida y las que no. En efecto, algunos valores son la expresión de fuerzas creadoras que la fortalecen, pero, también los hay que lo son por la costumbre y, de este modo, actúan debilitándola. Téngase por caso la cárcel. Esta ha sido heredada por la Modernidad, las sociedades modernas dependen de ella para funcionar. Pero, es importante preguntar qué es lo que se consigue con la cárcel que pueda nombrarse como creador, qué es lo que ofrece para intensificar el vivir, a qué fines 
sirve si no permite el florecimiento de la vida, por qué hay que pagar su precio. Para Kostenwein (2015) es evidente que la cárcel hace malvado al preso y embrutece al administrador/vigilante. No hay que tener tanto reparo, de manera descriptiva, lo que puede afirmarse es que tanto el preso como el administrador/vigilante están afectados de maldad y brutalidad. Los Derechos Humanos no consiguen frenar este proceso inevitable de decadencia, tanto del preso como de la sociedad que imagina en la cárcel las posibilidades de limpiar su mala conciencia y de esconder su capacidad de destrucción.

\section{Referencias}

Agamben, G. (2006). Lo abierto. El hombre y el animal. Buenos Aires, Adriana Hidalgo Editora.

Agamben, G. (2007). Infancia e historia. Ensayo sobre la destrucción de la experiencia. Buenos Aires, Adriana Hidalgo Editora.

Arenas, L. y Cerezo, A. (2016). «Realidad penitenciaria en Colombia: la necesidad de una nueva política criminal». Revista Criminalidad. 58 (2), p. 175-195.

Arrieta Burgos, E. (2017). «El sistema penitenciario y carcelario en Colombia: continuidades y discontinuidades foucaultianas», en A. Ruíz y D. Rincón (eds.), Michel Foucault: discurso y poder. 197-234. Medellín, Universidad Pontificia Bolivariana.

Bello, A. y Parra G. (2016). «Cárceles de la muerte: necropolítica y sistema carcelario en Colombia». Revista Universitas Humanística. 82, p. 365-391.

Benjamin, W. (1999). Ensayos escogidos. México, Ediciones Coyoacán.

Berlant, L. (2011). El corazón de la nación. Ensayos sobre política y sentimentalismo. México, Fondo de Cultura Económica.

Buck-Morss, S. (2005). Hegel y Haití. La dialéctica del amo-esclavo: una interpretación revolucionaria. Buenos Aires, Norma.

Butler, J. (2006). Vida precaria. El poder del duelo y de la violencia. Buenos Aires, Paidós.

Carrasco Jiménez, E. (2008). «Nietzsche y su visión del derecho penal». Polis. 21, p. $1-21$.

Dávila Londoño, L. F. (2015). «Derecho y la Violencia: Una Polémica Relación Pensada desde Nietzsche y Foucault». Revista CES Derecho. 6 (2), p. 108-120.

Deleuze, G. (2006). Conversaciones. 1972-1990. Valencia, Pre-Textos.

Elhart, R. F. (2018). «La pena según Nietzsche. Revista pensamiento penal». Recuperado de: http://www.pensamientopenal.com.ar/doctrina/47132-pena-segun-nietzsche

Foucault, M. (1999), Estética, ética y hermenéutica. Obras esenciales. Volumen III. Barcelona, Paidós.

Foucault, M. (2005). Historia de la sexualidad. 1 - la voluntad de saber. Buenos Aires, Siglo $X X \mid$

Foucault, M. (2006). Historia de la locura en la época clásica. Tomo I. México, Fondo de la Cultura Económica.

Foucault, M. (2010). La verdad y las formas jurídicas. Barcelona, Gedisa.

Foucault, M. (2012). El poder, una bestia magnifica. Sobre el poder, la prisión y la vida. Buenos Aires, Siglo XXI.

Hobsbawm, E. (1998). Historia del siglo XX. Buenos Aires, Crítica.

Huertas, O., Suárez, Y. y Morales, I. (2014). «Derechos humanos en la prisión en Colombia». Revista Diálogos de saberes. 14, p. 79-94.

Huertas, 0. (2015). «Sistema penal y hacinamiento carcelario. Análisis al estado de cosas inconstitucionales en las prisiones colombianas». Revista Jurídica Derecho. 2(3), p. 15-24.

Hunt, L. (2009). La invención de los derechos humanos. Barcelona, Tusquets. 
INPEC, Instituto Penitenciario y Carcelario de Colombia (2019). Informe estadístico diciembre 2018. Versión digital disponible en http://www.inpec.gov.co/web/guest/ estadisticas/informes-y-boletines/-

Kant, I. (1988). Lecciones de ética. Barcelona, Crítica.

Kant, I. (2009). Filosofía de la historia. México, Fondo de Cultura Económica.

Kostenwein, E. (2015). «Para releer Vigilar y castigar: Nietzsche, el cuerpo y la prisión» Revista crítica penal y poder. 9, p. 236-254.

Lemm, V. (2012). Nietzsche y el pensamiento político contemporáneo. Chile, Fondo de Cultura Económica.

León, J., Ruiz, H. y Serrano, J. (2013). «Drama humano en los centros penitenciarios y carcelarios de Colombia». Revista al Derecho \& al Revés. 8(8), p. 71-80.

Marx, K. (2009). La cuestión judía. México, Anthropos-Universidad Autónoma Metropolitana.

Mate, R. (2018). El tiempo, tribunal de la historia. Madrid, Trotta.

Muñoz Gaviria, D. A. (2005). «El evolucionismo social y la sociobiología especulativa en los autores de la degeneración de la raza: raza y evolución en Colombia entre 1900 y 1940». Revista Educación y Pedagogía. XVII (42), p. 131-144.

Nietzsche, F. (2014). «Humano, demasiado humano», en Obras completas. Volumen III. 59-272. Madrid, Tecnos.

Nietzsche, F. (2016a). «De la genealogía de la moral. Un escrito polémico», en Obras completas. Volumen IV. 439-560. Madrid, Tecnos.

Nietzsche, F. (2016b). «Ecce Homo. Cómo llega uno a ser lo que es», en Obras completas. Volumen IV. 773-859. Madrid, Tecnos.

Nietzsche, F. (2016c). «Así habló Zaratustra. Un libro para todos y para nadie», en Obras completas. Volumen IV. 65-279. Madrid, Tecnos.

Ossa López, M. F. (2016). La cárcel en Colombia. Espacio para la venganza y la reincidencia. Medellín, Unaula.

Piñeres Sus, J. D. (2016). «Antropología e idealidad», en A. Hincapié García y Escobar García (eds.), Modernidad y política. Sobre la pregunta antropológica. 19-42. Medellín, Unaula.

Sánchez Meca, D. (2000). «La tiranía del espíritu y sus formas», en J. E. Esteban Enguita y J. Quesada (eds.), Política, historia y verdad en la obra de F. Nietzsche. 219-238. España, Universidad de Burgos.

Sánchez Santiago, A. (2017). «Aproximación al concepto de genealogía en Nietzsche y en Foucault». La torre del Virrey. Revista de Estudios Culturales. 22, p. 1-8.

Zuleta Pardo, M. (2010). «La moral de la crueldad». Nómadas. 33, p. 13-30. 